\title{
Effectivity of imatinib therapy for the management of chronic myeloid leukemia patients MM Hossain ${ }^{1}$, MO Baki ${ }^{2}$, TE Nur $^{3}$, ZF Jesmin ${ }^{4}$
}

\begin{abstract}
Background: First generation tyrosine kinase inhibitor, imatinib revolutionized the treatment of chronic myeloid leukaemia, and is now the front line therapy. Imatinib provides substantial cytogenetic and molecular remission, with minimal normal hematopoiesis suppression or side effects and is now first line therapy.
\end{abstract}

Objective: The aim of this prospective study was to determine the efficacy of imatinib therapy in the management of chronic myeloid leukemia in Bangladesh.

Methods: This prospective study was done from June 2012 to May 2018. In this period we treated eight chronic myeloid leukaemia patients with imatinib, in Khulna division, Bangladesh.

Results: Majority of the patients (50\%) were in the age group of 21-30 years. Three patients died as because those patients were too poor to continue drugs. Another 5 patients were in good health and continuing follow up monthly. Among five patients, one patient have two healthy son.

Conclusion: Imatinib therapy is an effective treatment regimen in the management of chronic myeloid leukaemia. The best result can be obtained if CML is dignosed earlier.

\section{Introduction}

Chronic Myeloid Leukemia (CML) is a myeloproliferative disorder with an incidence of 12 cases per 100,000 adults. It accounts for approximately $15 \%$ of newly diagnosed cases of leukemia in adults. ${ }^{1}$

Diagnosis of CML is facilitated by cytogenic analysis of the cells and by measurement of leukocytic acid phosphatase values. Also diagnostic feature is the presence of abnormal chormosome 22, the philadelphia choromosome phl. The long arm of chromosome 22 is translocated usually to choromosome 9 but occasionally to other chormosomes. It is present in over $90 \%$ of cases. ${ }^{2}$

A philadelphia negative juvenile CML which occurs in young children, often with enlargement of the liver and spleen, extensive lymphadenopathy and eczema. The neutrophil alkaline posphatase score is normal and the level of foetal haemoglobin is increased. There is a monocytosis to $>1.0 \times 109 / \mathrm{L}$ and clonal cytogenetic change. It responds poorly to treatment. ${ }^{3}$

Major discoveries in diagnosis and treatment of chronic myeloid leukemia (CML) were achieved in the 1990's when CML became the targeted therpy in oncology. First generation tyrosine kinase inhibitor, imatinib revolutionized the treatment of CML, and is now frontline therapy. Imatinib provides substantial cytogenetic and molecular remissions, with minimal normal hematopoiesis suppression or side effects. ${ }^{4}$

Frontline therapy. Three tyrosine kinase inhibitors (TKIS), imatinib, nilotinib, and dasatinib are approved by the United States Food and Drug Administration for first line treatment of patients with newly diagnosed CML in chronic phase (CMLCP). Clinical trials with 2nd generation TKIs reported significantly deeper and faster responses; their impact on long term survival remains to be determined. Salvage therapy for patients who fail frontline therapy, second-line options include second and third generation TKIS. Although second and third generation TKIS are potent and selective, they exhibit unique pharmacological profiles and response patterns relative to different patient and disease characteristics such as patients' comorbidities, disease stage, and BCR ABLI mutational status Patients who develop the

1. Md Mokter Hossain PhD, Assistant Professor (Pathology) Khulna Medical College, Khulna. (E-mail: mokterhossain4351@yahoo.com)

2. Mollah Obayedullah Baki MD, Professor (Radiation Oncology) and Ex-director, NICRH, Mohakhali, Dhaka.

3. Tamanna-E-Nur MD, Assistant Professor (Pathology), Gazi Medical College, Khulna.

4. Zannatul Ferdous Jesmin FCPS, Associate Professor (Gynae and Obs), Khulna Medical College, Khulna. 
T3151 "gatekeeper" mutation display-resistance to all currently available TKIS except ponatinib. Allogeneic stem cell transplantation remains an important therapeutic option. For patients with CML-CP who have failed at least two TKIS and for all patients in advanced phase disease. ${ }^{1}$

Imatinib is $95 \%$ bound to plasma proteins and has a molecular weight of 590. Drugs that are highly bound to plasma proteins or have molecular weights higher then 500 have limited placental transfer. In cantrast, high concentration of imatinib are detected in breast milk. ${ }^{5}$

One of the great sucess stories of modern hematology is reaching its next and possibly final phase. The achievement of treatment free remissions in stable deep molecular responders with chronic myeloid leukemia (CML) may be equivalent to cure. Although only the minority of patients achieve treatment free remissions, the absolute numbers of patients currently in discontinuation studies and in durable treatment free remissions (40-60\%) are impressive and argue for a change in the treatment strategy for CML. The progress since last year cannot be overlooked. 6

The goal of this study is to define patients in whom treatment can be stopped safely and to establish a strategy for treatment discontinuation. ${ }^{7}$

\section{Material and methods}

This study was carried out at a private pathology and onco-consultation center, Khulna and Fatema Rahman cancer clinic and research center, Khulna during June 2012 to May 2018. A total number of 08 (Eight) patients with splenomegaly having no criteria of exclusion were included this study. Study area is in Khulna division, Bangladesh.

Inclusion Criteria: Patients having splenomegaly with peripheral blood and bone marrow findings suggesting chronic myloid leukaemia. Exclusion Criteria: Patients having splenomegaly but peripreral blood or bone marrow study suggests other diseases than chronic myeloid leukemia.

Response was based on investigation and clinical findings. All patients visited the clinics with peripheral blood film examination, total complete blood count, liver function tests \& kidney functions tests.

\section{Results}

A total of 08 (Eight) patients were included. out of total 8 cases, 04 were male $(50 \%)$ and 4 were female $(50 \%)$. Male and female ratio is $(1: 1)$. out of total cases, $(50 \%)$ patients are in the age group of 21-30 years.

\section{Table 1}

Age and sex distribution of study cases $(n=8)$

\begin{tabular}{lcccccc}
\hline $\begin{array}{l}\text { Age in } \\
\text { year }\end{array}$ & $\begin{array}{c}\text { Nos } \\
\text { Male }\end{array}$ & $\begin{array}{c}\% \\
\text { male }\end{array}$ & $\begin{array}{c}\text { No } \\
\text { female female }\end{array}$ & $\begin{array}{c}\% \\
\text { Total }\end{array}$ & $\%$ \\
\hline $11-20$ & 0 & 0 & 01 & 12.5 & 01 & 12.5 \\
$21-30$ & 02 & 25 & 02 & 25 & 04 & 50 \\
$31-40$ & 0 & 0 & 01 & 12.5 & 01 & 12.5 \\
$41-50$ & 1 & 12.5 & 0 & 0 & 01 & 12.5 \\
$51-60$ & 1 & 12.5 & 0 & 0 & 01 & 12.5 \\
\hline
\end{tabular}

\section{Table II}

Duration of treatment with remarks

\begin{tabular}{|c|c|c|c|c|}
\hline $\begin{array}{l}\text { SI. } \\
\text { No. }\end{array}$ & $\begin{array}{l}\text { Age in } \\
\text { Years }\end{array}$ & Sex & $\begin{array}{l}\text { Dure } \\
\text { of tre }\end{array}$ & on \\
\hline 1 & 18 & $\mathrm{~F}$ & 03 & $\begin{array}{l}\text { Delivered a son \& died } \\
\text { for discontinuation }\end{array}$ \\
\hline 2 & 22 & $\mathrm{~F}$ & 02 & Died for discontinuation \\
\hline 3 & 22 & M & 02 & $\begin{array}{l}\text { Well responding \& } \\
\text { Blood count-normal }\end{array}$ \\
\hline 4 & 23 & $\mathrm{~F}$ & 07 & $\begin{array}{l}\text { Delivered a son in } \mathrm{KMCH} \\
\& \text { another at home }\end{array}$ \\
\hline 5 & 24 & M & 01 & Died for discontinuation \\
\hline 6 & 58 & M & 05 & Well responding \\
\hline 7 & 50 & M & 01 & $\begin{array}{l}\text { Well responding \& } \\
\text { continuing therapy }\end{array}$ \\
\hline 8 & 35 & $\mathrm{~F}$ & 01 & $\begin{array}{l}\text { Well responding } \& \text { on } \\
\text { follow-up }\end{array}$ \\
\hline
\end{tabular}

Among our 8 patients, three died due to discontinuation of imatinib therapy. Those patients were very poor and cannot continue the drugs due to lack of money. Other five patients are also poor but taking drugs with the help of kind people of the society and they are well. One patient deliverd two healthy sons and one of the son was delivered in Gynae and Obs. Dept., Khulna Medical College and this is first time in Bangladesh. 
Table III

Characteristics of CML Patients in Study Caes

$(n=8)$

\begin{tabular}{lll}
\hline Characteristic & Number & $\%$ \\
\hline
\end{tabular}

Fever

03

37.5

Generalised weakness

04

Malaise

03

37.5

Anaemic

splenomegaly

08

100

All patients complained left hypochondriac uneasiness and splenomegaly is detected on palpation and on sonologically.

\section{Discussion}

Known etiological factors of CML are ionizing radiation, benzene etc. but in these cases etiological factor are not clear. We do not know whether their mother was under radiological exposure during the said pregnancy. The most frequent symptoms of CML are asthenia associated with a feeling of tension in the left hypochondrium resulting from splenomegaly. Fever, bone pain and haemorrhage are less frequent. Our patients also complained of asthenia $\&$ feeling of tension in left hypochondriac region. On clinical examination, there was also hepatosplenomegaly. ${ }^{2}$

Laboratory tests are essential for establishing a diagnosis of CML. Complete blood count with differential and platelets always shows leukocytosis $(>30,000 / \mathrm{mm})$, which may reach extremely high levels $(>500,000 / \mathrm{mm})$. At the time of diagnosis, the leukocytes are $>100,000 / \mathrm{mm}$ in $70-90 \%$ of cases, and spontaneous cyclical variations in their number are frequntly observed. The number of immature cells are less than $20 \%$, metamyelocytes and myelocytes predominant. There are increase in basophils, eosinophils and monocytes, which are often associated with a moderate degree of anaemia, the number of platelets are increased in approximately $50 \%$ of patients, and greater than $100000 /$ cumm, may be observed during the course of the disease. Hyperuricaemia are infrequent because of increased nucleic acid metabolism. Bone marrow aspiration is not useful for diagnosis. But bone marrow biopsy shows considerable hyperplasia of the granulocytic series and, occasionally, of magakaryocytic series, associated with medullary fibrosis in $30-40 \%$ cases. $^{2}$ Our patients are also anemic with presence of immature cells $30 \%$ and basophils $3-5 \%$. Total white blood cells count were $1,00,000-1,50,000 / \mathrm{mm} 3$. The number of platelet were 2,00,000-2,50,900/mm. ${ }^{3}$ Bone marrow biposy was not possible due to technical reason. So bone marrow aspiration were done, which revealed CML.

Three clinical stages of CML are recognized, which are important in terms of predicting the prognosis as well as planning of treatment of the disease. The three clinical stages of CML including the 1 . Chronic phase 2. The accelerated phase 3 . The blastic phase. Approximately $80-95 \%$ of patients with CML are diagnosed in the choronic phase of the disease, which can lasts for a few months to about 4 to 5 years. The chronic phase can usually be controlled with medications. Our patients were on choronic phase during diagnosis and were well being with medication for long time. Nearly $80 \%$ of patients with CML will. progress from chronic phase to the accelerated phase of the disease, which is a more advanced stage of the disease. The third stage of the disease of CML is known as blastic phase and is the most advanced stage of the disease, because $20 \%$ or more immature, leukaemic white blood cells called blasts are formed in the bone marrow and the blood. Blastic crisis are the most frequent cause of death (70$80 \%)$. In another cases, the cause of death is secondary to progressive bone marrow aplasia, complications related to chemotherapy or infections or haemorrhage, not associated with the blastic crisis. ${ }^{2}$ Our patients are still on chronic phase due to better management with drugs. They were on accelerated phase after changing the drug regimen and become chronic when again giving the previous regimen.

Monitoring can be performed using either a molecular or cytogenetic test, or both, depending on local facilities and on the degree of molecular standardization of the local laboratory. ${ }^{8}$

Molecular testing must be performed by RQ-PCR on buffy coat of more than $10 \mathrm{ml}$ of blood to measure BCR-ABLI transcripts level, which is expressed as BCR-ABL $1 \%$ on the IS. ${ }^{9}$

If cytogenetics is used, it must be performed by CBA of marrow cell metaphases, counting at least 20 metaphases, at 3, 6 and 12 months until a CCyR is achieved, and then every 12 months.

Limitations of the study are molecular or cytogenetic test are not available in our center. Most of the patients are poor and cannot visit qualified doctors. So our patient number are 
small. On the other hand most of the patients cannot continue drugs due to financial problem.

\section{Conclusion}

Imatinib therapy is a successful low cost treatment regimen in the management of chronic myeloid leukaemia but it needs close follow up.

\section{References}

1. Jabbour E, Kantarjian H:Chronic myeloid leukemia: 2016 update on diagnosis, therapy, and monitoring. Am J Hematol, 1991: 252-65

2. Hossain MM, Baki MO, Islam MS, Rashid AKMM; Juvenile Chronic Myeloid Leukaemia. A Case report. Bangladesh Cancer Reports; 2003; 2; 55-59.

3. Hoffbrand AV, Moss PAH. "Essential Haematology" 6th ed. Wiley Blackwell Publications 2008; p 221

4. Ault P, Cortes J: Planned Pregnancy for a patient with Chronic Myelold Leukemia. The Internet Journal of Oncology.2010 Vol: 7:2
5. Russell M A, Carpenter M W, Akhtar MS, Lagattuta $\mathrm{T}$ F, Egorin MJ: Perinatal/neonatal case presentation. Imatinib mesylate and metabolite concentrations in maternal blood placenta and breast milk Journal of Perinatology; 2007; 27; 242249

6. Hehman R. Innovation in hematology Perspective: CML 2016. Haematologica 2016;101(6): 657-659

7. Hughes TP, Ross DM. Moving treatment free remission into mainstream clinical practice in CML. Blood. 2016; 12 8: 17-23

8. 0, Brien S, Abboud CN, Akhtari M, et al. Clinical Practice Guidelines in Oncology. Chronic Myelogenous Leukemia Versionl. National Comprehensive Cancer Network (NCCN). 2013

9. Freeman BL, Blair A, Lubin J. Mortality from lymphohematopoitic malignancies among workers in formaldehyde industries; The national Cancer institute Cohort. J Natt Cancer inst. 2009;101:751761. 